\title{
ROUSSEAU: DA PROPRIEDADE PRIVADA À ALIENAÇÃO
}

Fernando Henrique Ferreira*

Resumo: O trabalho aqui apresentado dedica-se à apresentação e discussão do problema da propriedade privada acompanhando as análises do segundo Discurso. O objetivo é compreender as relações propostas pelo autor entre a alienação do homem e o surgimento da propriedade privada. A exposição estará concentrada em elucidar o problema à luz do contexto político, assim como proposto por Rousseau.

Palavras chave: Rousseau-ilumismo-desigualdade-propriedade-alienação

\section{Introdução}

A propriedade privada vem sendo um dos problemas essenciais sobre os quais se debruça a filosofia política moderna, particularmente quando se pensa em Jean-Jacques Rousseau. Considerada como a manifestação no plano histórico-concreto da corrupção moral do homem social, ela amplia as dificuldades de conciliação entre os interesses individuais e aquele da coletividade. Essa noção tem um lugar central no pensamento do filósofo iluminista, já que se traduz em uma espécie de "caixa de pandora", o local onde estaria contido todo o mal da humanidade. Por essa razão, o presente trabalho parte da ideia rousseauniana de degeneração da essência humana que se amplia com a introdução da propriedade privada, para acompanhar e compreender os seus desdobramentos e a nova configuração que adquire nas teorias políticas

\footnotetext{
* Formado em Filosofia pela Universidade Federal de São Paulo (UNIFESP), membro do Grupo de Estudos Rousseau (GER) e do Grupo de Pesquisa Rousseau e a Filosofia Francesa do lluminismo do CNPq Tem como objetivo trabalhar na área de filosofia política com foco no período moderno francês e alemão.

ffilosofiaunifesp@gmail.com
} 
posteriores. Ao explicitar com clareza as relações entre a propriedade privada e o conceito de alienação em Rousseau, é possível compreender o lugar que ocupam nas análises do processo social e político das teorias dos filósofos posteriores. Vejamos como o autor articula dentro de sua filosofia os conceitos de propriedade privada e alienação.

\section{1 - 0 grito da natureza}

No que diz respeito ao filósofo iluminista, se toda sua obra é permeada pela política, inclusive sua crítica à civilização que culmina na crítica à desigualdade social, a propriedade privada e seus efeitos na corrupção do homem terá uma face política determinante. Todavia, há um aspecto a ser considerado que diz respeito também ao âmbito de sua existência para além da sociedade. Ou seja, o homem considerado não mais em relação aos demais, mas em relação a si mesmo. Portanto, para pensar a propriedade privada em Rousseau, consideremos antes o homem que dela se apropria pela primeira vez.

\footnotetext{
O verdadeiro fundador da sociedade civil foi o primeiro que, tendo cercado um terreno, lembrou-se de dizer isto é meu e encontrou pessoas suficientemente simples para acreditá-lo. Quantos crimes, guerras, assassínios, misérias e horrores não pouparia ao gênero humano aquele que, arrancando as estacas ou enchendo o fosso, tivesse gritado a seus semelhantes: "Defendei-vos de ouvir esse impostor; estareis perdidos se esquecerdes que os frutos são de todos e que a terra não pertence a ninguém!" (ROUSSEAU, 1973, p. 265)
}

Deste modo, para determinar quem é esse homem é preciso considerar o seu processo de desenvolvimento, razão pela qual, se faz necessário retomar o estado originário, isto é, o estado de natureza. Ou seja, uma "dimensão" de existência na qual o homem está sujeito às sensações e aos impulsos da Natureza e na qual já estão em germe todas as faculdades virtuais. Tais faculdades terão o seu desenvolvimento desencadeado pela ação da perfectibilidade, faculdade de auto-aperfeiçoamento que irá conduzir o homem à superação das adversidades impostas pela Natureza, a uma cooperação mutua e, finalmente, à instituição da vida em sociedade. A partir do ingresso na vida social, o homem passa a dominar o que até então constituía a extensão de seu corpo, a Natureza. As descrições do segundo Discurso sobre o nascimento da agricultura e da arte 
de trabalhar metais demonstram o desenvolvimento do aparelho mental e intelectual humano, ao mesmo tempo em que a consciência de si levando-o a distanciar-se de sua natureza tende a conduzi-lo à própria alienação. $O$ processo é bastante complexo para ser exposto em poucas linhas, mas é fundamental para a compreensão do lugar que a corrupção moral adquire, sobretudo após a introdução da propriedade privada, quando então será deflagrado o processo de crescente desigualdade social. É importante, nesse momento, a determinação da distinção entre desigualdade no estado de natureza e a desigualdade entre os homens no estado social, já que se trata de demonstrar a responsabilidade das instituições humanas na degeneração do homem.

[...] cabe agora reconstituir o processo ambivalente de transformações que, mediante a ação da perfectibilidade, conduzirá a um desenvolvimento brilhante das faculdades humanas e, ao mesmo tempo, a uma perversão de suas disposições primitivas. De uma condição de integração com a natureza circundante e de independência de seus semelhantes, o homem evoluirá para uma situação de independência da natureza e de dependência em relação ao outro homem (SALINAS FORTES, 1989, p.58).

\section{2 - Da pura essência para pura aparência}

O desenvolvimento hipotético do homem, que Rousseau utiliza, deixa subescrito a relação entre essência e aparência, sendo o homem em seu estado primitivo, a essência, e o homem em estado social, a mera aparência. Esse desenvolvimento ao qual o autor remete a todo momento, deixa demasiadamente claro que é um progresso que levou séculos para se perpetuar. A compreensão da essência é fundamental, uma vez que o homem se degenera a partir de seu reconhecimento, e tem na propriedade privada, um grande aumento de tal degeneração, uma vez que a vida em sociedade é concebida, segundo Rousseau, a partir da instituição da propriedade, e em sociedade o homem distancia-se de sua essência rapidamente, pois emancipa-se da natureza ao mesmo tempo que se aprisiona nas meras aparências.

É com a introdução da propriedade que esse estado de juventude será destruído. E começa a ser elaborada a ideia de propriedade, de que algo me pertence com exclusividade, de que posso dispor de algo em condições absolutas, com exclusão de todos os demais. Estas também me excluem da posse e do uso dos bens de que se imaginam proprietários. A noção de propriedade não é uma ideia inata que acompanha o homem desde os tempos primitivos, mas é uma ideia adquirida, resultante de um aperfeiçoamento das "luzes" A partir de determinando momento, os homens que nada possuíam de seu e tudo partilhavam no seio da tribo, passaram a manter sob seu domínio exclusivo os frutos de seu trabalho ou a terra que trabalhavam (SALINAS FORTES, 1989, p. 62). 
É somente a partir da instauração da propriedade privada que o homem é retirado de uma vida simples e natural. A propriedade marca um ponto importante na história do homem, pois é a partir dela que o homem começa a se agrupar, constituindo famílias, e assim, deixando sua vida nômade. Antes de sua instituição, o homem é um ser livre, sendo movido apenas por seus instintos mais elementares, como alimentar-se quando tem fome, dormir quando tem sono, beber quando tem sede, e mantém relações com seus iguais apenas quando necessário. Sua liberdade é garantida pela natureza, pois nada pode prende-lo, ou arrancar-lhe seu maior bem. Portanto, é somente a partir do desenvolvimento de suas faculdades que o homem começou a degenerar-se, e começa a alienar seu maior bem, sua liberdade, tendo seu inicio a partir de seu reconhecimento, assim, começando a construir a sua prisão, que é perpetuada com a instituição da propriedade. Deste modo, há de ser atentado que a alienação do homem é a sua perda de si, a perda de sua essência, ou seja, o distanciamento entre o homem e sua natureza. Cabendo ser ressaltado que a degeneração do homem foi caminhando a passos lentos até a instituição da propriedade, pois ela não é o inicio da alienação e das desigualdades, porém é mediante sua criação que se desenvolve e amplia rapidamente esses males.

\section{3 - Conclusão}

Portanto, refletir a propriedade privada dentro das conjeturas rousseaunianas, é antes pensar a política, a forma de inserção social do homem nas sociedades contemporâneas. A relação com a natureza será a todo instante retomada, uma vez que ela é o início e ponto de chegada de toda a obra de Rousseau. Ademais, cabe aqui esclarecer as diferenças preponderantes entre o homem social e o homem do estado de natureza, assim como a alienação do homem em sociedade. Sendo o homem natural desprovido de sentimentos, será o descolamento da natureza, a partir da instituição da sociedade, que faz surgir no homem os sentimentos, as paixões que culminam na desigualdade. Uma forma de abordar um dos problemas resultantes desse percurso investigativo é buscar determinar se a propriedade privada tem origem no trabalho, e se é a partir dela que surge a alienação do homem. A saída apontada por Rousseau será instituída no Contrato Social; uma sociedade que permita ao homem permanecer em sua autenticidade, um ser capaz de intervir na 
vida social de forma harmônica, retomando o equilíbrio originário do estágio anterior, e garantindo uma liberdade igualitária ${ }^{1}$.

\section{REFERÊNCIAS BIBLIOGRÁFICAS}

ROUSSEAU, Jean-Jacques. Discurso sobre a Origem e os Fundamentos da Desigualdade entre os Homens. (Col. Os Pensadores). São Paulo: Abril Cultural, 1978.

. O contrato Social. (Col. Os Pensadores). São Paulo: Abril Cultural, 1978. Discurso sobre a Origem e os Fundamentos da Desigualdade entre os Homens

(Col. Os Pensadores). São Paulo: Abril Cultural, 1978.

PRADO JR, Bento. A retórica de Rousseau e outros ensaios (Org. Franklin de Mattos). São

Paulo:Cosac Naify, 2008

SALINAS FORTES, Luiz Roberto. Rousseau: o bom selvagem. São Paulo: FTD, 1989.

Paradoxo do Espetáculo: Política e Poética em Rousseau. São

Paulo: Discurso Editorial, 1997.

DELLA VOLPE , Galvano. Rousseau e Marx: a liberdade igualitária

\footnotetext{
${ }^{1}$ Termo utilizado por Galvano Della Volpe no livro - Rousseau e Marx: a liberdade igualitária.
} 